DOI 10.37882/2223-2982.2020.06.31

\title{
КЛАССИФИКАЦИЯ ПЕРЕВОДЧЕСКИХ ОШИБОК ПРИ ПЕРЕВОДЕ КИНО- И ВИДЕОПРОДУКЦИИ С АНГЛИЙСКОГО НА РУССКИЙ ЯЗЫК
}

\section{CLASSIFICATION OF TRANSLATION ERRORS IN TRANSLATING FILM AND VIDEO PRODUCTS FROM ENGLISH TO RUSSIAN}

\section{Solovieva}

Summary: "There are errors in the translated work, just as there is oxygen in the air» - this idea of the Japanese art critic and writer Kobayashi can be defined as an epigraph to the article.

Moreover, translation errors are an integral part of it, and their classification is an integral part of research aimed at the development of translation studies. Moreover, there is no generally accepted point of view both in translation studies and in modern linguistics on the typology of translation errors. This is especially true for the classification of translation errors in translating film and video products from English to Russian, since translation studies still consider audio - visual communication as something insignificant and cannot determine the place of new types of translation in movies, TV and radio programs, and advertising.

The article presents classifications of errors in translation from English to Russian by various authors, in terms of their adequacy for film and video production.

Keywords: modern linguistics, translation studies, film production, translation process, classification of translation errors, translation process, translation result.

\author{
Соловьева Валерия Юрьевна \\ Ассистент, Московский государственный областной \\ университет. \\ vusoloveva@mail.ru
}

Аннотация: «В переводимом произведении существуют ошибки, как в воздухе существует кислород»[7], - эту мысль японского художественного критика и писателя Кобаяси можно определить как эпиграф к статье.

Тем более, что ошибки перевода являются неотъемлемой его частью, а их классификация представляет собой неотъемлемую часть исследования, направленных на развитие переводоведения. Тем более, что общепринятой точки зрения как в переводоведении, так и в современной лингвистике по вопросу типологии переводческих ошибок просто не существует. Особенно это касается классификации переводческих ошибок при переводе кино- и видеопродукции с английского на русский язык, так как переводоведения, все еще рассматривает аудиовизуальную коммуникацию как нечто несущественное и не может определиться в отношении места новых разновидностей перевода в кино, теле- и радиопередачах, рекламе.

В статье приводятся классификации ошибок при переводе с английского на русский язык различных авторов, с точки зрения их адекватности для кинои видеопродукции.

Ключевые слова: современная лингвистика, переводоведении, кино-продукция, переводческий процесс, классификация ошибок перевода, переводческий процесс, результат перевода.
$\Pi$ еревод с позиции современной лингвистики представляет собой осмысленный результат интерпретирующей работы переводчика. При этом в этот момент работу переводчика можно сравнить с математиком, так как в одном и другом случае идёт поиск решений. Но при этом, переводчик находиться в более сложной ситуации, так как у него отсутствует алгоритм решения, которым наделен математик. Переводчику необходимо, во время поиска решения, осмыслить значения, не только конкретных слов, словосочетаний и фраз, но и увязать их в контексте.

Фактически каждый переводчик является творцом, потому и появляются авторские переводческие трактовки оригинала, базирующиеся на существовании нескольких методов прочтения текста. В свою очередь, трактовка начинается с восприятия текста, а заканчивается пониманием художественного текста. Главной причиной появления нескольких вариантов перевода текста, то есть вариативности перевода является разное понимание переводчиками одного и того же текста/ контекста. Такой феномен, возникает, во-первых, вследствие того, что переводчик осознанно может изменить, добавить или опустить что-либо в тексте перевода. вовторых, из-за разницы в интерпретации и понимании смысла оригинала переводчиком;

Перевод художественных фильмов и другой видеопродукции, помимо правильной интерпретации контекста, также увязан со спецификой перевода, которые кроются, как в диалектах, так и в региональных вариантах языка, а также увязаны, как с дефектов речи героев, так и с несуществующим языком и т. д.

Будучи ориентированным на оказание художественно-эстетического воздействия и достижение коммуникативно-прагматического эффекта, перевод в кино представляет собой разновидность художественного 
перевода, находясь при этом в прямой зависимости от избранной техники перевода, какими являются перевод на аудиторию, дубляж, озвучивание и перевод с субтитрами.[4]

Решению конкретных переводческих задач по обеспечению перевода в кино в соответствии с тем или иным видом перевода в значительной степени способствует наличие широкого кинематографического контекста, представляемого как видеорядом фильма, так и музыкальным шумовым оформлением.

Максимально приближенным к текстам, при переводе кино- и видеопродукции с английского на русский язык является перевод с субтитрами и это связано, в том числе с наличием письменной фиксации переводного текста. Субтитры, в виде текста приводятся в нижней части кадра.

К особенностям данного вида перевода, следует отнести пропуски и просто упразднение избыточных элементов. Все это делается для синхронизации субтитров с видеорядом. При этом на первом месте по упразднению стоят, во-первых, ритуальные формулы вежливости, во-вторых, повторы, и наконец, в-третьих, не влияющие на понимание разворачивающегося действия в картине диалоги на второго плана. Следует учесть, тот факт, что здесь переводчик сам принимает решение о второстепенности информации, которая содержится в звучащем в картине тексте. Переводчику важно не впасть в крайность и не превратить текст субтитров в своего рода стенографический информативный скелет исходного текста, полностью лишенный эмотивной функции, непосредственно воспринимаемой зрителем благодаря аудиоряду.

Дублированный перевод фильмов обладает, рядом преимуществ относительно предыдущего варианта, но при этом он осложнен, тем, что, во-первых, в обязательном порядке должна быть произведена синхронизация, как аудио, так и видеоряда, здесь речь идет и в отношении огубленных звуков, а также начала и окончания реплик персонажей. Это представляет собой сложную проблему, так как в разных языках имеют место расхождением, как в ритме и интонации, так и в произношении звуков. Во-вторых, следует учитывать, с одной стороны индивидуальные особенности артикуляции актеров и само положение актера, спиной, дальний план, крупный план по отношению к камере с другой. Совершенно очевидно, что артикуляция актера очень сильно воздействует на степень восприятия текста после перевода, так как одни, например, делают паузу перед произнесением реплики, но на экране видны движения его губ, он как бы вспоминает или перебирает нужные звуки, другой наоборот, говорят, практически не разжимая губ.
Перевод в кино в любой описанной выше форме подчинён чётким законам, которые являются характерными для практически всей переводческой деятельности. Но следует обратить внимание на то, что на визуальное восприятие ориентирован перевод с субтитрами, а слуховое восприятие, ориентировано на дублирование.

В этом свете, перевод «голос за кадром» является наиболее выигрышным с токи зрения непосредственно качества перевода. Единственным технически ограничением при переводе «голос за кадром» является его ориентированность на зафиксированное на пленке визуальное изображение, не позволяющее выходить за жестоко заданные временные рамки демонстрации фильма.

Закадровый перевод может быть, как одноголосым, так и двухголосым, и многоголосым, представляя собой слаженную работу целой команды актеров.

На первом этапе работы с художественным фильмом на иностранном языке переводчик сталкивается с необходимостью адаптации перевода. Адаптация как способ достижения соответствующего коммуникативного эффекта предполагает, что «некоторые предметные ситуации, выведенные в оригинальном речевом произведении, могут быть превратно истолкованы получателем текста перевода» [3]

Эти переводческие сложности, с которыми сталкивается переводчик, в конечном итоге могут приводить ошибкам в переводе и/или переводческим ошибкам.

Определим сам термин «переводческая ошибка». Ошибка представляет собой набор словосочетаний, таких, как отступление от правил, отклонение от правильного, стандартного, нарушение требований грубая неточность.

Одним из основных требований к переводу является передача содержания оригинала, посему, нарушение этого однозначно воспринимается как ошибка.

Так, в качестве ошибки может рассматриваться только так называемое «смысловое искажение», т. е. искажение смысла, при котором соответствующее высказывание или отрывок текста будет понят неверно. Прочие недостатки текста воспринимаются лишь как стилистические погрешности, роль которых в смысловой структуре текста имеет весьма небольшое значение.[1]

Анализируя разнообразные типологии переводческих ошибок, следует акцентировать внимание на первопричинах их совершения. При этом следует отметить, что ошибки перевода носят, как правило, бессознательный характер. С давних времен известно, что в недостаточной образованности переводчика кроются причины 
переводческих ошибок. Исходя из данного посыла, касающегося природы ошибок, механизм их исправления должен быть, ориентирован на расширение индивидуального опыта переводчика в познании окружающей действительности, как языковой, так и внеязыковой.

Недостаточная образованность переводчика проявляется, во-первых, в слабом знании языка оригинала и, во-вторых, в недостаточном знании «предмета мысли автора», то есть того, о чем идет речь в тексте оригинала. Невнимательное прочтение текста оригинала может также быть связано с недостатком филологической образованности. В результате того что у переводчика не развита «языковая чуткость», он оказывается неспособным уяснить особенности стиля переводимого произведения. [2]

На рисунке 1 в наглядном виде представлена типология причин переводческих ошибок.

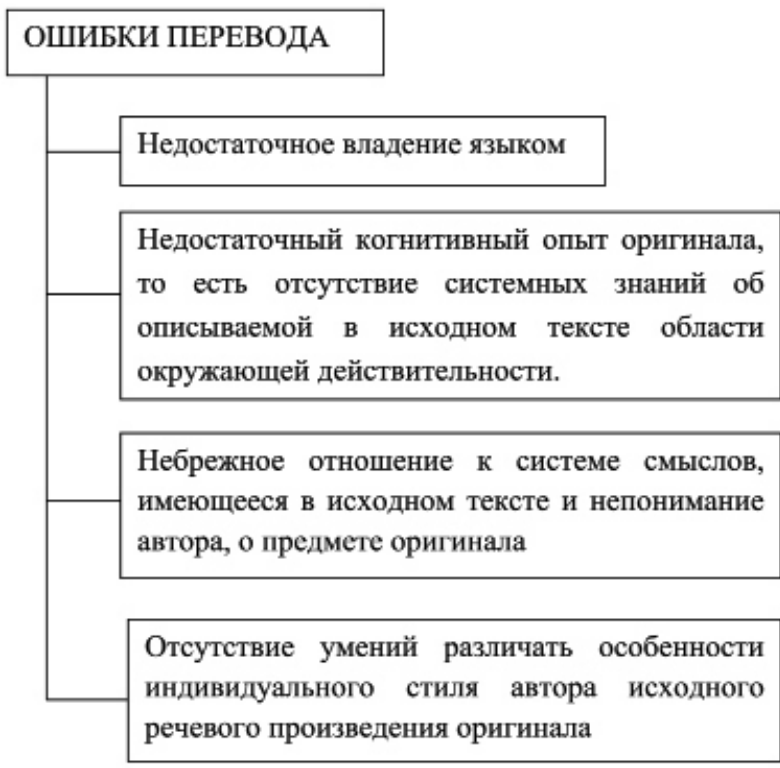

Рис. 1. Типология причин переводческих ошибок

Представленные на схеме - рисунок 1 причины ошибок, взаимосвязаны, и касаются компетенции, знаний, психологического состояния языковой личности переводчика, а также условий, в которых ему приходится воспринимать исходное сообщение.

Анализ ошибок переводчика, подводит к мысли о том, что невежество и безграмотность несовместимы с переводческой деятельностью.

Иной вариант классификации приводиться в статье М.А. Куниловской. Естественно, что представленная типология в большей степени ориентирована на письменные тексты, посему для наглядности приводятся комментарии, касающиеся перевода кино- и видеопродукции с английского на русский язык.
1. Содержательные, смысловые ошибки, которые можно разделить на буквализмы и вольности.

Буквализм представляет собой ошибку, смысл которой заключается в том, что при переводе используется самое популярное значение, а не ищется подходящее для данного случая значения слова. Сюда же относят дословный или пословный перевод. Буквальный перевод - это результат переводческой ошибки, возникающей как на первом этапе - в процессе прочтения и понимания исходного текста, так и на втором - при передаче его смысла средствами переводящего языка.[5]

Вольность представляет собой передачу ключевой информации без учета формальных и семантических компонентов исходного текста. В рамках осуществления переводе кино- и видеопродукции с английского на русский языка основным является смысловая передача сюжета, посему данную ошибку следует исключить.

2. Ошибки в трансляции исходного содержания функционально не мотивированные отклонения от содержания оригинала, различающиеся по степени дезинформирующего воздействия:

а) Искажения - это субъективно обусловленные отклонения содержания перевода от оригинала, в результате которых прагматический потенциал текста перевода не соответствует прагматическому потенциалу исходного текста (вводит в заблуждение реципиента относительно предмета сообщения, вызывает неадекватные представления).

б) Неточности - это отклонения от содержания оригинала, характеризующиеся меньшей степенью дезинформирующего воздействия; немотивированные опущения или добавление информации, не искажающее полностью содержание оригинала, но требующее уточнения.

в) Неясности - это функционально-содержательные изъяны перевода, затемняющие смысл высказывания, достаточно четко выраженный в исходном тексте; часто возникают из-за неудобоваримости синтаксических конструкций. Могут быть связаны с неудачным выбором слова или структуры фразы, либо обусловлены неадекватным использованием или неиспользованием переводческого приема.

3. Языковые ошибки, нарушающие нормы и узус переводящего языка. Эти ошибки делятся на: лексические, грамматические, стилистические, орфографические и пунктуационные.

Лексическая ошибка - это ошибка, связанная с неправильным использованием основного или контекстуального значения слова, а также нарушение норм сочетаемости слов в языке перевода. 
Грамматическая ошибка - это нарушение грамматических (в том числе синтаксических) норм языка перевода, не приводящее к искажению смысла оригинала.

Стилистическая ошибка - это использование слова, конструкции или стилистического средства, не соответствующего по своим функционально-языковым свойствам той жанрово-стилистической разновидности текстов, к которой принадлежит перевод.

Орфографическая ошибка, теоретически могут иметь место в результате перевода и использования субтитров при переводе кинофильмов, и вообще любой видео продукции, но так как они представляют собой ошибка в правописании слов языка перевода, то встречаются крайне редко.

Пунктуационная ошибка, с точки зрения перевода кинофильмов, и иной видео продукции, также встречаются крайне редко, так как сигнализируют о несоблюдение правил пунктуации языка перевода.

В классификации, основанной на работах Льва Константиновича Латышева имеют место следующие виды ошибок.

1. Ошибки в трансляции исходного содержания функционально не мотивированные отклонения от содержания оригинала, различающиеся по степени дезинформирующего воздействия

2. Искажения.

3. Неточности.

4. Неясности

5. Ошибки в адаптации содержания и форм его выражения к новым лингвоэтническим условиям восприятия, их причина - неумение компенсировать языковые расхождения, иными словами ошибки в оформлении текста на языке перевода. Классифицируются по видам единиц языка и речи.

6. Лексическая ошибка

7. Грамматическая ошибка

8. Стилистическая ошибка

9. Орфографическая ошибка

10. Пунктуационная ошибка. [6]

В представленной типологии определения имеют место только в новых видах ошибок, не определенных ранее.
Следует обратить, внимание, на тот факт, что фактически любая классификация, рассмотренная в статье, была сформирована конкретным автором, на базе перевода исключительно письменного текста. Фактически с момента появления первых печатных книг возникла острая необходимость их перевода и печатания на другом языке, а сам процесс перевода берет своё начало в глубокой древности и там толмачи, как раньше назывались переводчики, в большинстве своём переводили оратора непосредственно во время говорения. Сегодня, в условиях глобализирующегося мира наблюдается удивительное явление, и читатель постепенно уступает место зрителю. Это связано с тем, что визуальное представление может поведать намного больше, чем, печатное слово. Помимо слов, в кинофильмах, и иной видео продукции, процесс коммуникации построен на базе активного применения жестов, мимики, тона голоса.

Показательным примером, может служить мировая премьера фильма «Матрица», состоявшееся 5 ноября 2003 года, которое проходила в разных уголках планеты, охватив одномоментно 80 стран мира, включая такие города, как Москва, Париж, Лондон, Лос-Анжелес, Токио, Пекин и многие, многие другие, при этом фильм был переведен на 43 языка.

Для перевода художественных кинофильмов, и вообще любой видео продукции и с английского на русский язык, подойдет следующая классификация, переводческих ошибок:

- ошибки в трансляции;

- искажения;

- неточности;

- неясности;

- ошибки в адаптации.

Долгое время исследователи обходили своим вниманием перевод в кино, несмотря на лингвистическую, культурологическую, экономическую и политическую важность данного феномена. В рамках данного исследования приведены разнообразные типологии ошибок переводы, встречающихся в научных изданиях и статьях по эрратология и/или «теория ошибок» и предложена классификация ориентированная на переводческие ошибки при переводе кино- и видеопродукции с английского на русский язык.

\section{ЛИТЕРАТУРА}

1. Бузаджи Д.М., Гусев В.В., Ланчиков В.К., Псурцев Д.В. Новый взгляд на классификацию переводческих ошибок.-М.: ВцП ,2009. - 118 с.

2. Гарбовский Н.К. Семь вопросов дидактики перевода или sсороз-дидактика переводческой деятельности // Вестн. Моск. ун-та. Сер. 22. Теория перевода. 2012. № 4. С. 41.

3. Гарбовский Н.К. Теория перевода: Учебник. М.: Изд-во Моск. ун-та, 2004. - 544 с.

4. Горшкова, В. Е. Теоретические основы процессоориентированного подхода к переводу кинодиалога (на материале современного французского кино) : автореф. дис. ... д-ра филол. наук. Иркутск, 2006. URL : http://vak ed.gov.ru /announcements/filolog/GorshkovaVE.doc. - 34 c. 
5. Кокунова Ю.В. буквализмы в переводах художественных фильмов: причины и следствия // Перевод и сопоставительная лингвистика. Выпуск № 8. URL: https://cyberleninka.ru/article/n/bukvalizmy-v-perevodah-hudozhestvennyh-filmov-prichiny-i-sledstviya/viewer. C. 24 - 28.

6. Латышев Л.К. Технология перевода. Уч. пос. по подготовке переводчиков - ML: HBИ - Тезаурус, 2000. - 280 c.

7. Гу Цзюньлин, Хуан Чжунлянь Система классификации переводческих ошибок. // Вестник Московского университета. Сер. 22. Теория перевода. 2016. № 3. C. $26-40$

( С Соловьева Валерия Юрьевна (vusoloveva@mail.ru).

Журнал «Современная наука: актуальные проблемы теории и практики»

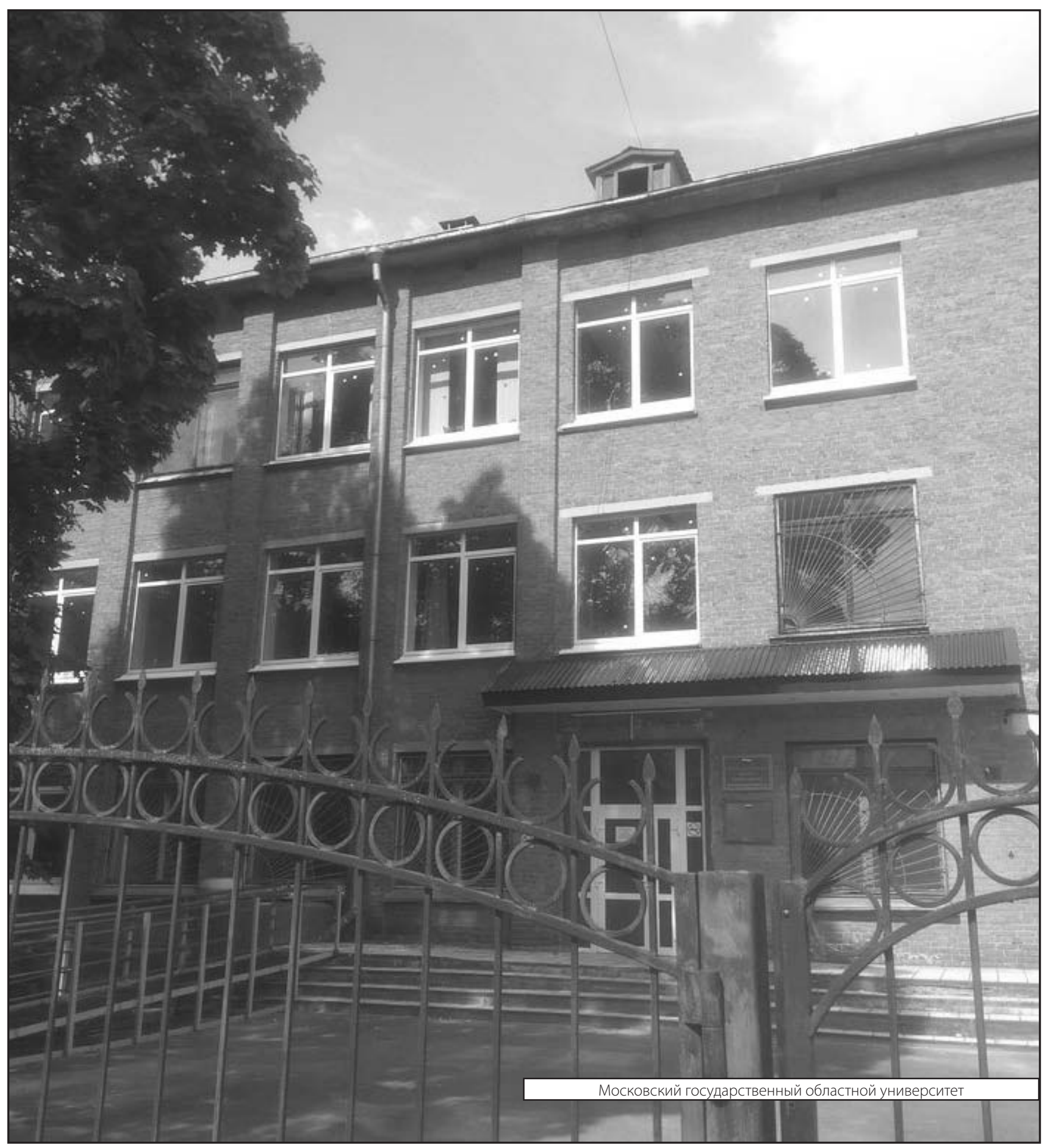

